\title{
Effect of the interproximal contact level on the perception of smile esthetics
}

\section{Wpływ miejsca kontaktu międzyzębowego na odbiór estetyki uśmiechu}

\author{
Mohammad Ramadan Rayyan ${ }^{A-F}$ \\ Department of Prosthodontics, College of Dentistry, Riyadh Elm University, Saudi Arabia \\ A - research concept and design; $\mathrm{B}$ - collection and/or assembly of data; $\mathrm{C}$ - data analysis and interpretation; \\ $D$ - writing the article; $E$ - critical revision of the article; $F$ - final approval of the article
}

Address for correspondence

Mohammad Ramadan Rayyan

E-mail:mohammadrayyan1979@gmail.com

Funding sources

None declared

Conflict of interest

None declared

Received on February 13, 2019

Reviewed on March 15, 2019

Accepted on May 29, 2019

Published online on September 30, 2019

Cite as

Rayyan MR. Effect of the interproximal contact level on the perception of smile esthetics. Dent Med Probl. 2019;56(3):251-255. doi:10.17219/dmp/109704

DOI

$10.17219 / \mathrm{dmp} / 109704$

Copyright

๑ 2019 by Wroclaw Medical University

This is an article distributed under the terms of the

Creative Commons Attribution 3.0 Unported License (CC BY 3.0)

(https://creativecommons.org/licenses/by/3.0/)

\begin{abstract}
Background. Many dental and facial components affect smile esthetics, and dental professionals'opinions regarding dental esthetics may not always coincide with the perceptions and expectations of the patients.

Objectives. This work is designed to determine the dimensions of the interproximal contact areas that are considered the most or least attractive according to a group of laypersons, dentists and technicians.

Material and methods. Two photographs of female and male smiles showing a full smile were taken with a Nikon ${ }^{\circledR}$ camera and digitally altered using Adobe ${ }^{\circledR}$ Photoshop. The length of the interproximal contact areas was altered to generate 2 sets of images ( 3 images of the female and 3 images of the male smile in each set). A group of 40 laypersons, 40 dentists and 40 dental technicians were asked to select the most and the least attractive image in each set.

Results. An interproximal contact ratio of 50:40:30 [\%] was the most attractive arrangement $(40.00 \%$ and $38.33 \%$ for the female and male smiles, respectively). The 'reversed' ratio of 30:40:50 [\%] was the least attractive to the participants (57.50\% and $44.17 \%$ for the female and male smiles, respectively). There were differences in the rankings of the most and the least attractive smiles among the 3 groups of evaluators.

Conclusions. The 'ideal' interproximal contact ratio of 50:40:30 [\%] is perceived to be the most attractive. However, the smile esthetics perception among dental professionals is not always in agreement with the perception of laypersons.
\end{abstract}

Key words: esthetics, dental, proximal, smile attractiveness

Słowa kluczowe: estetyka, zębowy, proksymalny, atrakcyjność uśmiechu 


\section{Introduction}

Smile is a significant determinant of dental and facial esthetics. Several dental and facial components affect smile esthetics, and a harmonizing esthetic smile requires the successful integration of dental and facial composition. ${ }^{1}$ Esthetic treatment should always be preceded by a thorough analysis of both facial and dental composition. ${ }^{2}$

The perception of esthetics is influenced by one's social environment, culture and individual experiences. Considering dental professionals' scientific and professional background, their opinions regarding dental esthetics may differ from the expectations of their patients. ${ }^{3-11}$ Thus, it is imperative for dental professionals to continuously study changes in the perception of smile esthetics in their communities. ${ }^{12}$

The length and sequence of the interproximal contact area - an area where 2 adjacent teeth appear to touch - in the maxillary anterior teeth have been considered important factors affecting dental esthetics. ${ }^{13}$ Normally, the interproximal contact area between the 2 central incisors is located at the incisal third. The level of the interproximal contact area moves apically as we move posteriorly. ${ }^{14}$ For the most attractive smile, the 50:40:30 rule has been proposed, in which the contact area between the maxillary central incisors constitutes $50 \%$ of the length of the central incisors; the contact area between the maxillary lateral incisor and the central incisor is $40 \%$ of the length of the central incisor; and the contact area between the maxillary canine and the maxillary lateral incisor is $30 \%$ of the length of the central incisor. ${ }^{15}$ However, further studies are needed to investigate the impact of the length and sequence of the proximal contact area on the perception of smile esthetics.

Therefore, this study aimed to investigate which interproximal contact area dimensions are considered the most attractive among laypersons, dentists and techni- cians. Furthermore, this study assessed whether there are any differences in the smile esthetic perception between dental professionals and laypersons.

\section{Material and methods}

Ethical approval was obtained from the institutional review board of Riyadh Elm University, Saudi Arabia, before conducting the study (approval No. RC/IRP/2016/398). The sample size calculation was done using the free software G*Power, v. 3.1.9.213 (http://www.psychologie.hhu.de/arbeitsgruppen/allgemeine-psychologie-und-arbeitspsychologie/gpower.html). Assuming the significance level of alpha at $\leq 0.05$ and an effect size of 0.26 , the sample size required to achieve $90 \%$ power was 120 subjects (40 in each group).

Two photos were taken with a professional Nikon ${ }^{\circledR}$ camera (D5200; Nikon Corp., Shinagawa, Tokyo, Japan), 1 for a male smile and 1 for a female smile. The photos were then altered digitally using the Adobe ${ }^{\circledR}$ Photoshop CS6 software (Adobe Systems Inc., San Jose, USA) to produce standard, bilaterally symmetrical images. The standard images were modified to produce 2 sets of smile images in order to evaluate the effect of the interproximal contact area on perceived smile esthetics.

In the $1^{\text {st }}$ set, the levels of the interproximal contact areas of maxillary anterior teeth in the standard images were altered to produce 3 images for the female and $3 \mathrm{im}$ ages for the male smiles with a different order of the proximal contact lengths (Fig. 1):

- ideal - the ratio of the interproximal contact areas followed the 50:40:30 rule;

- equal - the interproximal contact areas were equal (50:50:50);

- reversed - the ratio of the interproximal contact areas was reversed (30:40:50).
A1

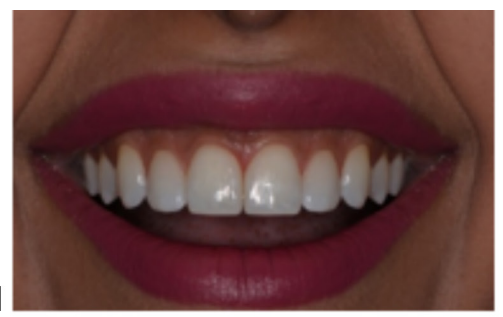

A2

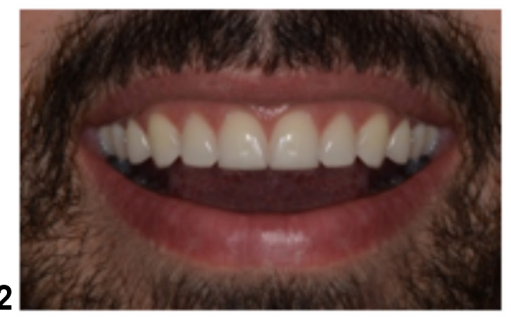

B1
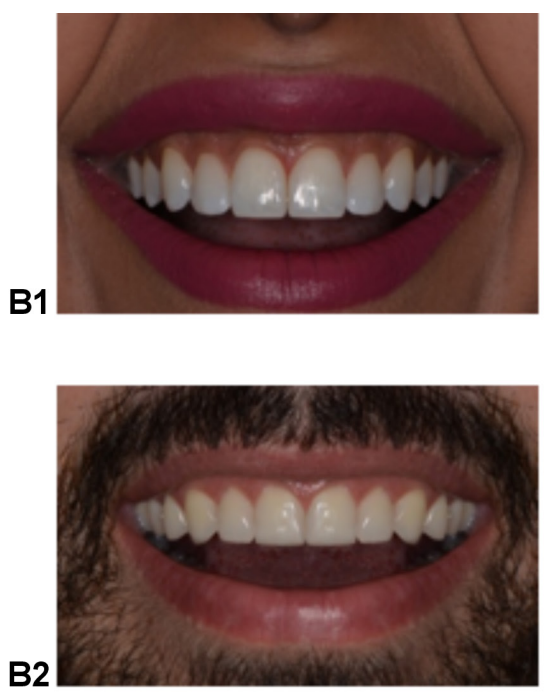

C1
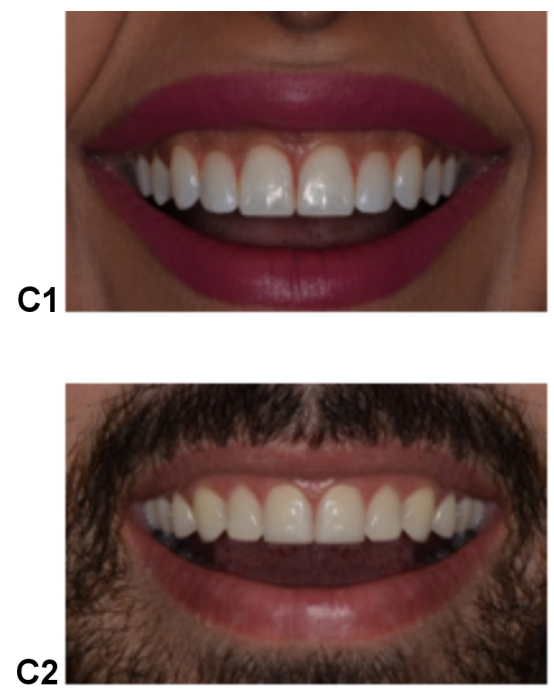

Fig. 1. The $1^{\text {st }}$ set of images with a different order of the proximal contact lengths

A1 and A2 - 'ideal' 50:40:30 [\%] ratio, female and male smiles, respectively; B1 and B2 - 'equal'50:50:50 [\%] ratio, female and male smiles, respectively;

C1 and C2 -'reversed' 30:40:50 [\%] ratio, female and male smiles, respectively. 
In the $2^{\text {nd }}$ set, the levels of all interproximal contact areas in the standard images were modified apically or coronally to produce 3 images for the female and 3 images for the male smiles with different proximal contact lengths (Fig. 2):

- reduced - the ratio of the interproximal contact areas was decreased (40:30:20);

- ideal - the ratio of the interproximal contact areas followed the 50:40:30 rule;

- exaggerated - the ratio of the interproximal contact areas was increased (60:50:40).

The ratios of interproximal contact lengths in all images were based on the length of the left maxillary central incisor.

The images were presented to the participants as slides, with 3 smile images on each slide, on a Samsung tablet screen, 8.4 inches, LTE (Galaxy Tab S; Samsung, Seoul, South Korea). Data collection was conducted via a secured online research platform (https://www.qualtrics.com). One hundred and twenty participants consented to participate in the study. The participants were divided into 3 groups: 40 laypersons; 40 dentists; and 40 dental technicians. Among all participants, 79 were males $(M)$ and 41 were females $(F)$. Their age ranged between 20 and 60 years with a median age of 31 years. The group of laypersons consisted of adults undergoing prosthodontic or restorative esthetic treatment (veneers or crowns). Only dentists practicing esthetic dentistry were included in the $2^{\text {nd }}$ group. The group of technicians comprised only ceramist technicians. Any participants complaining of visual impairment were excluded from the study.

The smile images were examined by each participant under adequate standard light and they were given enough time to render their final decision regarding their preference.
The statistical analysis of their responses was performed using the IBM SPSS Statistics for Windows software, v. 22.0 (IBM Corp., Armonk, USA). The $\chi^{2}$ tests were carried out to test for significant differences between the groups. The significance level was set at $p \leq 0.05$.

\section{Results}

For the $1^{\text {st }}$ set of images, the order of the proximal contact ratios was changed. The results show that the 'ideal' 50:40:30 ratio was considered the most attractive to the majority of the participants $(40.00 \%$ and $38.33 \%$ for the female and male smiles, respectively). The 'reversed' $30: 40: 50$ ratio was the least attractive arrangement to the participants $(57.50 \%$ and $44.17 \%$ for the female and male smiles, respectively) (Table 1 ).

The majority of the dentists and technicians selected the 'ideal' 50:40:30 ratio as the most attractive, both in the female and male smiles (F: $52.5 \%$; M: $35.0 \%$ and F: 42.5\%; M: 45.0\%, respectively). However, more laypersons selected the 'equal' 50:50:50 ratio for the female smile (F: 42.5\%) and the 'reversed' 30:40:50 ratio for the

Table 1. Smile esthetics perceived by the participants in terms of the interproximal contact area sequence ratio

\begin{tabular}{|l|c|c|c|c|}
\multicolumn{1}{|c|}{ Sequence ratio } & $\begin{array}{c}\text { Most } \\
\text { attractive }\end{array}$ & Middle & $\begin{array}{c}\text { Least } \\
\text { attractive }\end{array}$ & Total \\
\hline $\begin{array}{l}\text { Female smile } \\
\text { ideal 50:40:30 [\%] }\end{array}$ & $48(40.00)$ & $47(39.17)$ & $25(20.83)$ & 120 \\
reversed 30:40:50 [\%] & $28(23.33)$ & $23(19.17)$ & $69(57.50)$ & 120 \\
equal 50:50:50 [\%] & $44(36.67)$ & $50(41.66)$ & $26(21.67)$ & 120 \\
Male smile & & & & \\
ideal 50:40:30 [\%] & $46(38.33)$ & $44(36.67)$ & $30(25.00)$ & 120 \\
reversed 30:40:50 [\%] & $40(33.33)$ & $27(22.50)$ & $53(44.17)$ & 120 \\
equal 50:50:50 [\%] & $34(28.34)$ & $49(40.83)$ & $37(30.83)$ & 120 \\
\hline
\end{tabular}

Data presented as number (percentage).
A1

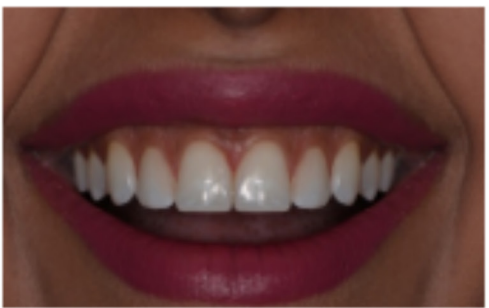

A2

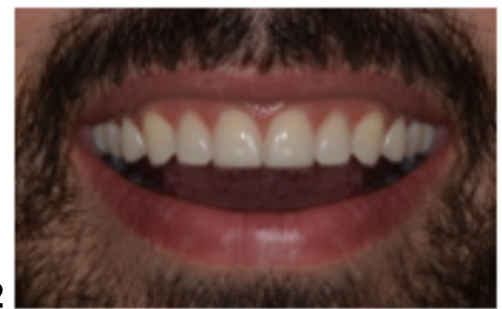

B1
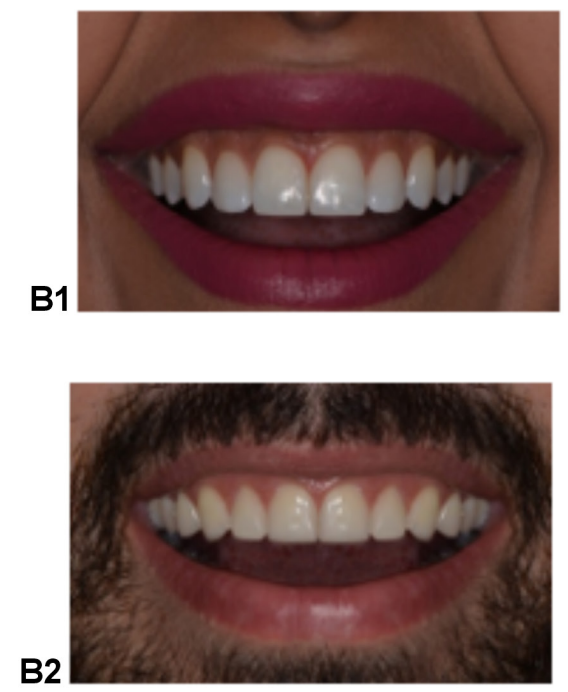

C1

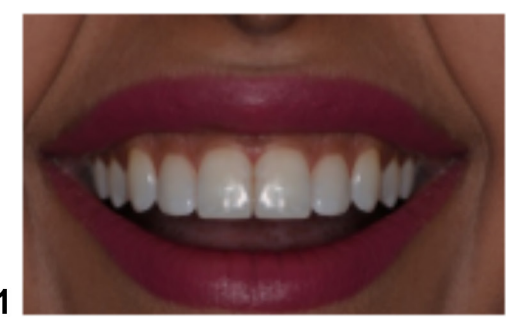

C2

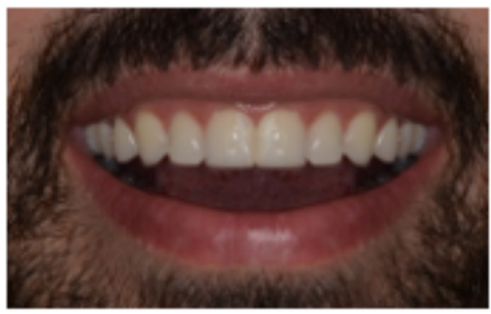

Fig. 2. The $2^{\text {nd }}$ set of images with different proximal contact lengths

A1 and A2 -'reduced' 40:30:20 [\%] ratio, female and male smiles, respectively; B1 and B2 - 'ideal' 50:40:30 [\%] ratio, female and male smiles, respectively; C1 and C2 -'exaggerated'60:50:40 [\%] ratio, female and male smiles, respectively. 
male smile (M: 42.5\%) as the most attractive. On the other hand, the majority of the dentists perceived the 'reversed' 30:40:50 ratio as the least attractive (F: 70.0\%; M: 55.0\%), as did the majority of the technicians (F: $57.5 \%$; M: 47.5\%). However, a higher percentage of laypersons selected both the 'ideal' 50:40:30 and 'equal' 50:50:50 ratios as the least attractive male smile.

No statistically significant differences in the ranking were found among the 3 groups ( $p=0.093$ for the female smiles; $p=0.507$ for the male smiles) (Table 2).

In the $2^{\text {nd }}$ set of images, the length of the interproximal contact areas was different. The 'ideal' 50:40:30 contact area length was considered the most attractive by the majority of the participants (F: $50.83 \%$; M: 38.33\%). The 'exaggerated' 60:40:50 length was the least attractive arrangement for the female smile (F: $61.66 \%$ ), whereas the 'reduced' 40:30:20 length was the least attractive for the male smile (M: 44.17\%) (Table 3).

Table 2. Univariate analysis for the association between perceived smile esthetics in terms of various interproximal contact area ratios and the type of respondent

\begin{tabular}{|c|c|c|c|c|}
\hline \multirow[b]{2}{*}{ Factor } & \multicolumn{3}{|c|}{ Respondent type } & \multirow[b]{2}{*}{$p$-value } \\
\hline & $\begin{array}{l}\text { dentist } \\
(n=40)\end{array}$ & $\begin{array}{c}\text { layperson } \\
(n=40)\end{array}$ & $\begin{array}{l}\text { technician } \\
(\mathrm{n}=40)\end{array}$ & \\
\hline $\begin{array}{l}\text { MA }(F) \\
\text { ideal 50:40:30 [\%] } \\
\text { reversed 30:40:50 [\%] } \\
\text { equal 50:50:50 [\%] }\end{array}$ & $\begin{array}{r}21(52.5) \\
5(12.5) \\
14(35.0)\end{array}$ & $\begin{array}{l}10(25.0) \\
13(32.5) \\
17(42.5)\end{array}$ & $\begin{array}{l}17(42.5) \\
10(25.0) \\
13(32.5)\end{array}$ & 0.093 \\
\hline $\begin{array}{l}\text { MA (M) } \\
\text { ideal 50:40:30 [\%] } \\
\text { reversed 30:40:50 [\%] } \\
\text { equal 50:50:50 [\%] }\end{array}$ & $\begin{array}{l}14(35.0) \\
13(32.5) \\
13(32.5)\end{array}$ & $\begin{array}{r}14(35.0) \\
17(42.5) \\
9(22.5)\end{array}$ & $\begin{array}{l}18(45.0) \\
10(25.0) \\
12(30.0)\end{array}$ & 0.507 \\
\hline $\begin{array}{l}\text { LA }(F) \\
\text { ideal 50:40:30 [\%] } \\
\text { reversed 30:40:50 [\%] } \\
\text { equal 50:50:50 [\%] }\end{array}$ & $\begin{array}{r}6(15.0) \\
28(70.0) \\
6(15.0)\end{array}$ & $\begin{array}{r}13(32.5) \\
18(45.0) \\
9(22.5)\end{array}$ & $\begin{array}{r}6(15.0) \\
23(57.5) \\
11(27.5)\end{array}$ & 0.109 \\
\hline $\begin{array}{l}\text { LA (M) } \\
\text { ideal 50:40:30 [\%] } \\
\text { reversed 30:40:50 [\%] } \\
\text { equal 50:50:50 [\%] }\end{array}$ & $\begin{array}{r}9(22.5) \\
22(55.0) \\
9(22.5)\end{array}$ & $\begin{array}{l}14(35.0) \\
12(30.0) \\
14(35.0)\end{array}$ & $\begin{array}{r}7(17.5) \\
19(47.5) \\
14(35.0)\end{array}$ & 0.139 \\
\hline $\begin{array}{l}\text { MA }(F) \\
\text { ideal 50:40:30 [\%] } \\
\text { exaggerated 60:50:40 [\%] } \\
\text { reduced 40:30:20 [\%] }\end{array}$ & $\begin{array}{r}22(55.0) \\
2(5.0) \\
16(40.0)\end{array}$ & $\begin{array}{l}18(45.0) \\
11(27.5) \\
11(27.5)\end{array}$ & $\begin{array}{r}21(52.5) \\
4(10.0) \\
15(37.5)\end{array}$ & 0.054 \\
\hline $\begin{array}{l}\text { MA }(\mathrm{M}) \\
\text { ideal 50:40:30 [\%] } \\
\text { exaggerated 60:50:40 [\%] } \\
\text { reduced 40:30:20 [\%] }\end{array}$ & $\begin{array}{l}14(35.0) \\
13(32.5) \\
13(32.5)\end{array}$ & $\begin{array}{r}14(35.0) \\
9(22.5) \\
17(42.5)\end{array}$ & $\begin{array}{l}18(45.0) \\
12(30.0) \\
10(25.0)\end{array}$ & 0.507 \\
\hline $\begin{array}{l}\text { LA }(F) \\
\text { ideal 50:40:30 [\%] } \\
\text { exaggerated 60:50:40 [\%] } \\
\text { reduced 40:30:20 [\%] }\end{array}$ & $\begin{array}{r}3(7.5) \\
29(72.5) \\
8(20.0)\end{array}$ & $\begin{array}{r}7(17.5) \\
16(40.0) \\
17(42.5)\end{array}$ & $\begin{array}{r}4(10.0) \\
29(72.5) \\
7(17.5)\end{array}$ & $0.017^{*}$ \\
\hline $\begin{array}{l}\text { LA }(\mathrm{M}) \\
\text { ideal 50:40:30 [\%] } \\
\text { exaggerated 60:50:40 [\%] } \\
\text { reduced 40:30:20 [\%] }\end{array}$ & $\begin{array}{r}7(17.5) \\
25(62.5) \\
8(20.0)\end{array}$ & $\begin{array}{r}7(17.5) \\
16(40.0) \\
17(42.5)\end{array}$ & $\begin{array}{r}5(12.5) \\
27(67.5) \\
8(20.0)\end{array}$ & 0.079 \\
\hline
\end{tabular}

Data presented as number (percentage).

MA - most attractive; LA - least attractive; $\mathrm{F}$ - female smile; $\mathrm{M}$ - male smile;

${ }^{*}$ statistically significant $(p \leq 0.05)$; the $x^{2}$ test.
Table 3. Smile esthetics perceived by the participants in terms of the interproximal contact area length ratio

\begin{tabular}{|l|c|c|c|c|}
\multicolumn{1}{|c|}{ Sequence ratio } & $\begin{array}{c}\text { Most } \\
\text { attractive }\end{array}$ & Middle & $\begin{array}{c}\text { Least } \\
\text { attractive }\end{array}$ & Total \\
\hline $\begin{array}{l}\text { Female smile } \\
\text { ideal 50:40:30 [\%] }\end{array}$ & $61(50.83)$ & $45(37.50)$ & $14(11.67)$ & 120 \\
exaggerated 60:50:40 [\%] & $17(14.17)$ & $29(24.17)$ & $74(61.66)$ & 120 \\
reduced 40:30:20 [\%] & $42(35.00)$ & $46(38.33)$ & $32(26.67)$ & 120 \\
Male smile & & & & \\
ideal 50:40:30 [\%] & $46(38.33)$ & $44(36.67)$ & $30(25.00)$ & 120 \\
exaggerated 60:50:40 [\%] & $34(28.34)$ & $49(40.83)$ & $37(30.83)$ & 120 \\
reduced 40:30:20 [\%] & $40(33.33)$ & $27(22.50)$ & $53(44.17)$ & 120 \\
\hline
\end{tabular}

Data presented as number (percentage).

The majority of the dentists and technicians selected the 'ideal' 50:40:30 ratio as the most attractive, both in the female and male smiles (F: $55.0 \% ; \mathrm{M}: 35.0 \%$ and F: $52.5 \%$; M: $45.0 \%$ ), whereas the majority of laypersons selected the 'ideal' 50:40:30 ratio in the female smile and the 'reduced' 40:30:20 ratio in the male smile as the most attractive (F: 45.0\%; M: 42.5\%). No statistically significant differences in the ranking were found between the 3 groups ( $p=0.054$ for the female smiles; $p=0.507$ for the male smiles) (Table 2).

In terms of the least attractive smiles, the 'exaggerated' 60:40:50 length ratio was selected by both the dentists (F: 72.5\%; M: 62.5\%) and the technicians (F: 72.5\%; M: 67.5\%), whereas more laypersons selected the 'reduced' 40:30:20 length ratio as the least attractive (F: 42.5\%; M: $42.5 \%$ ). The analysis revealed statistically significant differences in the ranking of the $2^{\text {nd }}$ set of images of the female smile between the 3 groups $(p=0.017)$ (Table 2 ).

\section{Discussion}

Presenting images of smiles to participants in order to investigate their perception of attractiveness regarding smile esthetics is a method which can be frequently found in the literature, though the specifics vary from study to study. In the current study, cropped images, showing only the subjects' smiles were used in order to eliminate the potential distraction of the evaluator's perception. ${ }^{16}$

The results show that the 'ideal' interproximal contact area ratio arrangement proposed by Morley and Eubank - 50:40:30 - is considered the most attractive among dentists and dental technicians. ${ }^{\text {acc.15 }}$ On the other hand, a higher percentage of laypersons selected the 'equal' arrangement for the female smile and the 'reversed' one for the male smile as the most attractive. Similarly, in examining the ratio of the length of the interproximal contact areas, the majority of the participants ranked the 'ideal' ratio (50:40:30) as the most attractive. One exception was the rating of the male smile by the layperson group, where a higher percentage found the 'reduced' ratio $(40: 30: 20)$ to be the most attractive. 
In agreement with previous studies, our findings revealed variations in the preferences of dental professionals and laypersons regarding smile esthetics. ${ }^{3,5,6,10,11}$ These variations, although minor, highlight the need for effective communication between dentists and dental technicians to ensure that the planned esthetic treatment meets the individual patient's expectations.

The interproximal contact areas can be altered by esthetic gingival surgeries, orthodontic treatment, or designing and contouring dental restorations. Moreover, when replacing missing teeth, the interproximal contact area represents the connector that joins pontics and retainers. It is common practice to increase the length of the connector area to ensure the strength and rigidity of fixed dental prostheses and to compensate for the recession of the interproximal papilla, which often follows tooth extraction. However, these alterations in the proximal contact area must be carefully planned to make sure they are within the acceptable esthetic range. ${ }^{5}$

The perception of esthetics could be affected by the interaction of multiple variables. In the current study, as with similar ones which preceded it, standardized photographs were used and only 1 esthetic variable was changed per set of images. This was done to isolate each variable and to investigate its individual effect on the perception of smile esthetics. Nevertheless, this limitation should be taken into consideration when interpreting the results of the current study.

\section{Conclusions}

The 'ideal' interproximal contact ratio (50:40:30) regarding the sequence and length is perceived as the most attractive arrangement, whereas the 'reversed' sequence ratio (30:40:50) and 'exaggerated' length ratio (60:50:40) are perceived as the least attractive arrangement. There are differences in perception between dental professionals and laypersons regarding the attractive order and length of proximal contact areas.

\section{ORCID iDs}

Mohammad Ramadan Rayyan (10) https://orcid.org/0000-0001-9677-1608

\section{References}

1. Nomura S, Freitas KMS, Silva PPCD, et al. Evaluation of the attrac tiveness of different gingival zeniths in smile esthetics. Dental Press J Orthod. 2018;23(5):47-57.

2. Omar H, Tai YT. Perception of smile esthetics among dental and nondental students. J Educ Ethics Dent. 2014;4(2):54-60.

3. Carlsson GE, Wagner IV, Odman P, et al. An international comparative multicenter study of assessment of dental appearance using computer-aided image manipulation. Int J Prosthodont 1998;11(3):246-254.

4. Kokich VO Jr, Kiyak HA, Shapiro PA. Comparing the perception of dentists and lay people to altered dental esthetics. J Esthet Dent. 1999;11(6):311-324.

5. Kokich VO, Kokich VG, Kiyak HA. Perceptions of dental professionals and laypersons to altered dental esthetics: Asymmetric and symmetric situations. Am J Orthod Dentofacial Orthop. 2006;130(2):141-151.
6. Foulger TE, Tredwin CJ, Gill DS, Moles DR. The influence of varying maxillary incisal edge embrasure space and interproximal contact area dimensions on perceived smile aesthetics. Br Dent J. 2010;209(3):E4

7. Fonseca Jardim da Motta A, Nelson Mucha J, Gomes de Souza MM. Influence of certain tooth characteristics on the esthetic evaluation of a smile. Dental Press J Orthod. 2012;17(3):e1-e7.

8. Cooper GE, Tredwin CJ, Cooper NT, Petrie A, Gill DS. The influence of maxillary central incisor height-to-width ratio on perceived smile aesthetics. Br Dent J. 2012;212(12):589-599.

9. Assad Duarte ME, Martins Machado R, Fonseca Jardim da Motta A, Nelson Mucha J, Trindade Motta A. Morphological simulation of different incisal embrasures: Perception of laypersons, orthodontic patients, general dentists and orthodontists. J Esthet Restor Dent. 2017;29(1):68-78.

10. Al Taki A, Hamdan AM, Mustafa Z, Hassan M, Abu-Alhuda S. Smile esthetics: Impact of variations in the vertical and horizontal dimensions of the maxillary lateral incisors. Eur J Dent. 2017;11(4):514-520.

11. Sulikowski AV, Yoshida A. Three-dimensional management of dental proportions: A new aesthetic principle: "The frame of reference". Quintessence Dent Technol. 2002;25:8-20.

12. Stappert CF, Tarnow DP, Tan JH, Chu SJ. Proximal contact areas of the maxillary anterior dentition. Int J Periodontics Restorative Dent. 2010;30(5):471-477.

13. Morley J, Eubank J. Macroesthetic elements of smile design. J Am Dent Assoc. 2001;132(1):39-45.

14. Krishnan V, Daniel ST, Lazar D, Asok A. Characterization of posed smile by using visual analog scale, smile arc, buccal corridor measures, and modified smile index. Am J Orthod Dentofacial Orthop. 2008;133(4):515-523.

15. Mollabashi V, Abolvardi M, Akhlaghian M, Ghaffari MI. Smile attractiveness perception regarding buccal corridor size among different facial types. Dent Med Probl. 2018;55(3):305-312.

16. Jørnung J, Fardal $\varnothing$. Perceptions of patients' smiles: A comparison of patients' and dentists' opinions. J Am Dent Assoc. 2007;138(12):1544-1553;quiz 1613-1614. 